
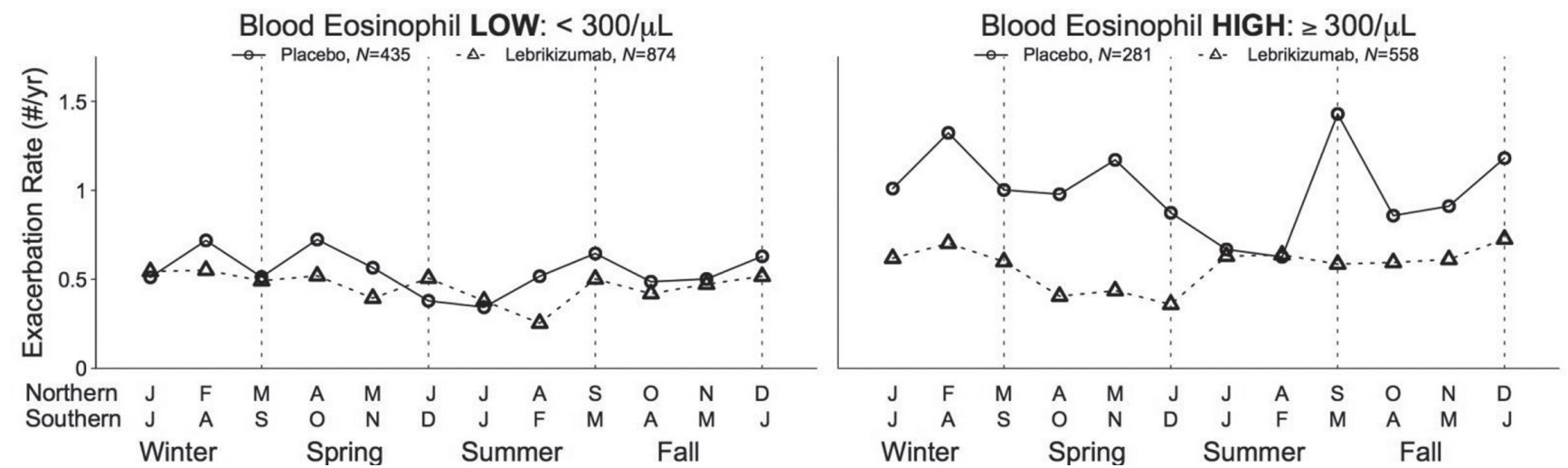

Abstract P157 Figure 1 Seasonal analysis of exacerbations in subjects defines by baseline blood eosinophil counts. Unadjusted exacerbation rates are plotted as a function monthe normalised by hemisphere. The month for corresponding hemispheric season are annotated in plot margins. Analyses for subject with baseline blood eosinophils $<300 / \mu \mathrm{L}$ or $>300 / \mu \mathrm{L}$ are plotted on left and right panels respectively.

year in August to 1.43/year in September). The 95\% confidence intervals for the per-month lebrikizumab treatment effect overlapped with zero in eosinophil-low patients for all calendar months. The maximum per-month treatment effects for eosinophil-high patients were observed during the autumn and spring months $(62.7[10.1,84.5] \%$ for September and $65.1[8.6,86.7] \%$ for May). The minimum per-month treatment effects were observed in the summer months $(11.3[-148.7,68.4] \%$ for July and $6.6[-166.0,67.2] \%$ for August).

Conclusions We conclude that seasonal spikes in exacerbations may be primarily dependent on Type 2 inflammatory processes. The molecular pathways underlying asthma exacerbations are heterogeneous and therapeutic strategies targeting Type 2 biology alone may have the greatest efficacy in limiting seasonal spikes in exacerbation rates. Overall, these data highlight that a significant proportion of asthma exacerbations may be independent of seasonal influences and/or Type 2 biology and that increased therapeutic efficacy may require targeting multiple distinct pathways in asthma.

\section{P158 FLUTICASONE FUROATE(FF)/VILANTEROL (VI) ONCE DAILY IMPROVES NIGHT-TIME AWAKENINGS IN ASTHMA}

${ }^{1} \mathrm{~N}$ Barnes, ${ }^{1} \mathrm{~L}$ Yates, 'MR Gibbs, ${ }^{2} \mathrm{R}$ Forth. 'GlaxoSmithKline Respiratory Global Franchise, London, UK; ${ }^{2}$ PAREXEL International, Research Triangle Park, USA

\subsection{6/thoraxjnl-2016-209333.301}

Introduction and objectives FF/VI, the first once daily inhaled corticosteroid/long-acting $ß 2$-agonist combination available for the treatment of asthma, has demonstrated a sustained 24 hour improvement in lung function and improvement in symptom-free 24 hour periods.

Methods Post-hoc analyses of diary card data from three Phase III studies were performed to examine whether there was an improvement in night-time awakening during the studies for those patients treated with the addition of vilanterol to fluticasone furoate. The diary card scale used is described below. Changes in night-time awakenings over the duration of the studies were analysed for percentage of patients with $\geq 50 \%$ symptom-free nights, including the time taken for $50 \%$ of patients to achieve 7 nights without symptoms.

Night-time Symptom Score:

$0=$ No symptoms during the night

$1=$ Symptoms causing me to wake once (or wake early)

2 = Symptoms causing me to wake twice or more (including waking early)

3 = Symptoms causing me to be awake for most of the night

4 = Symptoms so severe that I did not sleep at all

To be counted as symptom-free during the night the patient needed to record a score of 0 .

Results The percentage of patients with $\geq 50 \%$ symptom-free nights was generally higher in patients treated with FF/VI compared to either FF or FP alone (Table below). The time (in days) for $50 \%$ of patients to achieve 7 nights without symptoms was achieved sooner with patients treated with FF/VI compared to FF alone (Table).

Conclusions In general, night-time awakenings improved over time in asthma patients with FF/VI and improved faster with FF/ VI compared with FF or placebo. 
Abstract P158 Table 1 Treatment comparisons for \% patients with $\geq 50 \%$ symptom free nights over the study duration

\begin{tabular}{|c|c|c|c|}
\hline $\begin{array}{l}\text { HZA106827 (Weeks 1-12) } \\
\text { REF }\end{array}$ & $\begin{array}{l}\text { Placebo } \\
(n=203)\end{array}$ & $\begin{array}{l}\text { FF } 100 \\
(n=204)\end{array}$ & $\begin{array}{l}\text { FF/VI } 100 \\
(n=201)\end{array}$ \\
\hline$\%$ of patients & $35 \%$ & $46 \%$ & $59 \%$ \\
\hline Odds Ratio $(95 \% \mathrm{Cl})$ & & $\begin{array}{l}\text { FF vs } \mathrm{PbO}: \\
2.29 \\
(1.41,3.73)\end{array}$ & $\begin{array}{l}\mathrm{FF} / \mathrm{NI} \text { vs } \mathrm{PbO}: \\
4.66 \\
(2.84,7.66)\end{array}$ \\
\hline Odds Ratio $(95 \% \mathrm{Cl})$ & & & $\begin{array}{l}\text { FF/VI vs } \\
\text { FF 100: } \\
2.04 \\
(1.29,3.22)\end{array}$ \\
\hline $\begin{array}{l}\text { Time (days) when } 50 \% \text { of } \\
\text { patients } \\
\text { achieved } 7 \text { nights without } \\
\text { symptoms }\end{array}$ & $\begin{array}{l}\text { Did not occur } \\
\text { during study }\end{array}$ & 70 & 44 \\
\hline HZA106863 (Weeks 1-12) & FF 100 & FF/VI 100 & FF/VI 200 \\
\hline REF & $(n=346)$ & $(n=345)$ & $(n=345)$ \\
\hline$\%$ of patients & $42 \%$ & $43 \%$ & $48 \%$ \\
\hline Odds Ratio $(95 \% \mathrm{Cl})$ & & $\begin{array}{l}\text { FF/VI } 100 \text { vs } \\
\text { FF } 100: \\
1.33 \\
(0.93,1.91)\end{array}$ & $\begin{array}{l}\text { FF/NI } 200 \text { vs } \\
\text { FF/NI } 100: \\
1.23 \\
(0.87,1.74)\end{array}$ \\
\hline $\begin{array}{l}\text { Time (days) when } 50 \% \text { of } \\
\text { patients } \\
\text { achieved } 7 \text { nights without } \\
\text { symptoms }\end{array}$ & 86 & 64 & 48 \\
\hline HZA106829 (Weeks 1-24) & FF 200 & FF/VI 200 & FP 500 \\
\hline REF & $(n=193)$ & $(n=197)$ & $(n=195)$ \\
\hline$\%$ of patients & $41 \%$ & $51 \%$ & $46 \%$ \\
\hline Odds Ratio (95\% Cl) & & $\begin{array}{l}\text { FF/VI } 200 \text { vs } \\
\text { FF } 200: \\
1.59 \\
(0.99,2.55)\end{array}$ & \\
\hline Odds Ratio $(95 \% \mathrm{Cl})$ & & $\begin{array}{l}\text { FF/VI } 200 \text { vs } \\
\text { FP } 500: \\
1.09 \\
(0.69,1.74)\end{array}$ & \\
\hline $\begin{array}{l}\text { Time (days) when } 50 \% \text { of } \\
\text { patients achieved } 7 \text { nights } \\
\text { without symptoms }\end{array}$ & 111 & 72 & 84 \\
\hline
\end{tabular}

\section{P159 THERAPEUTIC BENEFIT OF MEPOLIZUMAB IN THE SCOTTISH MEDICINES CONSORTIUM (SMC) RESTRICTED SUB-POPULATION - A POST-HOC META-ANALYSIS OF PHASE IIB/III TRIALS}

${ }^{1}$ RA Mehta, ${ }^{2}$ CEA Hartmann, ${ }^{2} \mathrm{NB}$ Gunsoy, ${ }^{1} \mathrm{FC}$ Albers. ${ }^{1}$ GlaxoSmithKline, Research Triangle Park, USA; ${ }^{2}$ GlaxoSmithKline, Uxbridge, UK

\subsection{6/thoraxjnl-2016-209333.302}

Rationale The Scottish Medicines Consortium provides advice to NHS boards and Area Drug and Therapeutics Committees across Scotland about the status of newly licensed medicines. In June 2016 positive advice was issued for mepolizumab, an anti-IL-5 $\mathrm{mAb}$ licensed for adult severe refractory eosinophilic asthma, for use in a restricted sub-population: patients who have eosinophils of $\geq 150$ cells per microlitre $(0.15 \times 109 / \mathrm{L})$ at initiation of treatment and had $\geq 4$ asthma exacerbations in the preceding year or are receiving maintenance treatment with oral corticosteroids
(mOCS). Here we present the results for this sub-population comparing the effect of mepolizumab with placebo in this subgroup.

Methods Three randomised, double-blind, placebo-controlled studies of mepolizumab in severe eosinophilic asthma were identified, which used the licensed $100 \mathrm{mg}$ SC dose or the corresponding $75 \mathrm{mg}$ IV dose of mepolizumab. For analysis purposes, these two treatment arms were combined. A post-hoc meta-analysis assessing the key outcome measures in the three phase IIb/III trials (DREAM [NCT01000506] and MENSA [NCT01691521] with a sensitivity analysis including SIRIUS [NCT01691508]) were run for the sub-population using individual patient data.

Results The post-hoc meta-analysis included 197 patients from DREAM and MENSA and 251 when including the SIRIUS trial. The mean age was 51.2 and 51.3 years of which $62 \%$ and $64 \%$ were female, respectively. A 59\% (95\% CI: $0.31,0.55$; $\mathrm{p}<0.001)$ reduction in clinically significant exacerbations was seen in the meta-analysis of DREAM and MENSA (50\% [95\% CI: $0.40,0.64, p<0.001]$ sensitivity analysis with SIRIUS). The ACQ score showed an improvement of $-0.56 \quad(95 \%$ CI: $-0.79,-0.33 ; \mathrm{p}<0.001$ ) and -0.58 (95\% CI: $-0.79,-0.38$; $\mathrm{p}<0.001$, sensitivity analysis with SIRIUS). The SGRQ was only used in MENSA and SIRIUS and showed an improvement in total score of $-8.0(-12.0,-3.9, \mathrm{p}<0.001)$.

Conclusion Mepolizumab treatment was effective in SMC advice population (adult severe refractory eosinophilic asthma patients with a blood eosinophil count of $\geq 150$ cells $/ \mu \mathrm{L}$ at initiation of treatment, and $\geq 4$ exacerbations in the previous year or dependency on mOCS). The use of a post-hoc meta-analysis is a helpful approach to increase our understanding of mepolizumab's treatment effect in the SMC restricted sub-population.

Funding GSK (NCT01000506, NCT01691521, NCT01691508).

\section{P160 USE OF OMALIZUMAB IN FUNGAL ALLERGIC ASTHMA}

${ }^{1} \mathrm{HV}$ Patel, ${ }^{2} \mathrm{~B}$ Kane, ${ }^{2} \mathrm{P}$ Foden, ${ }^{2} \mathrm{~L}$ Holmes, ${ }^{2} \mathrm{GOG}$ Tavernier, ${ }^{1} \mathrm{~TB}$ Morris, ${ }^{2} \mathrm{DM}$ Ryan, ${ }^{2}$ RM Niven. 'University of Manchester, Manchester, UK; ${ }^{2}$ University Hospital of South Manchester, Manchester, UK

10.1136/thoraxjnl-2016-209333.303

Background The monoclonal anti-IgE agent Omalizumab holds an established place in the management of severe allergic asthma patients (GINA Step 5). Fungal allergic asthma possesses added complexity as fungi are ubiquitous in our environment and are capable of not only triggering asthma, but may grow, colonise and infect host tissue. Current treatment approaches include: Allergen avoidance, mucus reduction, control of bacterial infection, control of inflammation, reducing fungal burden and recently blockade of allergy using Omalizumab.

Aims/purpose Investigate the response to Omalizumab in severe asthma patients who are sensitised to fungal allergens compared to those who are non-fungal allergic. Current literature describes the use of Omalizumab in fungal allergic airways disease, though published data takes the form of case reports/series with limited total population.

Methods Retrospective cohort study of severe asthma patients treated with Omalizumab $(n=168)$. Patients were grouped into fungal or non-fungal allergy status, followed by a comparison of the change in a variety of clinical and physiological outcomes at 16 weeks and 52 weeks from baseline between these two groups. The change in Asthma Quality of Life Questionnaire (AQLQ) between baseline and 16 weeks was utilised as the primary outcome. Groups will be compared using an unpaired t-test or Chi- 